\title{
PURGE REDUCTION DEVICE: A GUIDE TO THE SELECTION OF GAS SEAL IN A FLARE SYSTEM
}

\author{
Akash Kumar \\ Department of Design and Engineering \\ Ador Welding Limited, Pune, Maharashtra, India
}

\begin{abstract}
The effect of gas seal in a flare system has been analyzed and investigated. Based on the commissioned flare, the effect of both molecular as well as velocity seal is observed and various pros and cons of both the seals are assessed. It is observed that the velocity seals are more economical from the construction point of view whereas molecular seal has the least purge rate but the calculation of purge rate presented that up to a certain diameter of tip, there is no significant difference in the purge gas quantity and that diameter was below 16 inch. The safety features are also discussed, though it is suggested that velocity seals must be installed along with liquid seal, it alone can also serve the purpose likewise molecular seals.
\end{abstract}

Keywords- Flare system, Velocity seal, Molecular seal, Purge rate, Liquid seal

\section{INTRODUCTION}

The flow of purge gas to the stack is normally a waste of valuable purge gas, but it is essential to prevent the explosion due to the rich mixture formed by combining flare gas with air. For economic reasons, the purge gas quantity used must be reduced so as to avoid the wastage of the inert gases. Due to this sole major reason, the seals are used in flare system to avoid ingress of air.

However, the ingress of air can also be prevented without using any type of sealing devices but the impact of that can be catastrophic as it requires a large amount of purge gas and if for any reason that purge rate is reduced, the air starts entering the stack through tip and cause sudden explosion leading to the system failure [1].

The whole flare system is assumed as an explosive device if any mishap is allowed due to which many safety devices are pre-installed in the system to eliminate such possibilities. The sealing devices to prevent such air ingress are as follows:

1. Liquid sealing device

2. Gas sealing device

As the name suggests, the liquid generally water is used as sealing fluid in the former while the latter use gas as sealing fluid. It is not valid to say that using any of these will

\author{
Sachin Phadatare \& Pradeep Deore \\ Department of Design and Engineering \\ Ador Welding Limited, Pune, Maharashtra, India
}

completely eliminate the ingress of air but can prevent the accumulation of air inside the stack to a limit so as to avoid flammable mixture which leads to explosion. As per API 521, the liquid seal is used as a secondary option to prevent flashback originating from the flare tip from propagating back to through the flare system because if it happens, the whole plant destruction can take place and therefore it is placed at the bottom of the stack but it becomes difficult to prevent flashback once a large amount of air gets entered inside the riser through tip and hence it is a common practice to place a gas seal between the riser and tip. So we can say that the Gas seal is the primary device which prevents any explosion due to formation of air/gas rich mixture and helps in maintaining oxygen level below an allowable limit.

\section{WHAT IS A GAS SEAL?}

Gas seal is a device used in flare systems which uses purge gas to avoid air ingress into the system. Purge gas (or "purge flow") is required to prevent air impingement in the process header when there is little or no process flow going to the flare (as in the case of a dedicated intermittent or ESD flare) [2]. Should air enter the flare stack, a release of process gas could result in a combustible mixture present within the flare in a restricted zone. The ignition of this air/gas mixture can result in an explosion and cause severe equipment damage. Air present in the stack can create a potentially explosive mixture with incoming flare gas. So, to eliminate such condition, two types of gas seals, usually located at/or below the flare tip are used: the buoyancy seal and the velocity seal. The usage or selection of the gas seal (buoyancy and velocity seal) is still uncertain and the criteria to choose between the two has been analyzed and presented in this paper. Air infiltration down the flare stack from wind or density effects can be mitigated by use of purge gas. If purge gas is required, the user shall assure the reliability of its supply. The amount of purge gas required can be reduced by the use of a purge-reduction seal.

\section{DEFINITIONS}

The two types of gas seals can be explained below: 


\section{International Journal of Engineering Applied Sciences and Technology, 2020 \\ Vol. 4, Issue 9, ISSN No. 2455-2143, Pages 272-275 \\ Published Online January 2020 in IJEAST (http://www.ijeast.com)}

1. Molecular seals: This seal is placed between the flare stack or riser and flare tip. As the name suggests, it typically uses the difference in densities of the purge gas and ambient air to keep the air from entering the flare system.

- If purge gas is lighter than air, it accumulates at the top of inner cylinder and forms a seal to prevent entry of air into the flare system [3].

- If the purge gas is heavier than air then it accumulates at the bottom of outer cylinder and forms a seal there to prevent air from entering the flare system.

- The vessel has an inspection port and a drain to allow trapped liquids to drain down the stack via a separate line. The material of construction is carbon steel, Incoloy etc.

2. Velocity seals (DPCS): This type of seal is the simplest of purge reduction seals and takes the form of a truncated cone normally made as an integral part of the flare tip. It provides the flare system with a physical barrier to air penetration down the inside wall of the riser and also maximizes the velocity of the purge gas, further reducing the risk of air ingress.

The action of such a seal is in two-fold [2]:

- It represents a smaller cross section area to the upward of the tip which reduces the amount of purge gas required for maintaining the fixed purge momentum;

- It allows flow of flare gas in the correct direction (upflow) which suffers less flowing friction losses than incoming air (downwards).

\section{DESIGN FEATURES}

\section{MOLECULAR SEAL}

A baffled cylinder arrangement (Fig.1.) forces the incoming air through two $180^{\circ}$ bends (one bend up and one bend down) before it can enter into flare stack. The two $180^{\circ}$ turns can cause liquid collection in the seal in which case a drain equipped with a loop seal (for example) is required [4]. The drain shall be kept open and protected from freezing in cold climates.

The major parts are:

- Shell (Inner, Intermediate and outer cylinder)

- Drain connection

- Lifting lugs

- Optional components as per industry requirement

\section{VELOCITY SEAL}

It is observed that a flare system is operated safely if the oxygen level below the seal is not more than 6 vol. $\%$ i.e. $50 \%$ of the concentration at which a flammable mixture is formed. Therefore the purge rate ensuring 6 vol.\% oxygen in the flare stack is the minimum safe purge rate [3].
As we know, velocity seal is made as an integral part of the tip and it consists of baffle plates arranged in the form of truncated cone, baffle to seal diameter ratio (as shown in fig.2) is the deciding factor for purge rate. As the ratio $d / D$ increases, the oxygen concentration below the seal increases so as to reach a flammable limit [2]. Therefore, if the purge rate of $0.012 \mathrm{~m} / \mathrm{sec}$ as recommended by API 521 is maintained

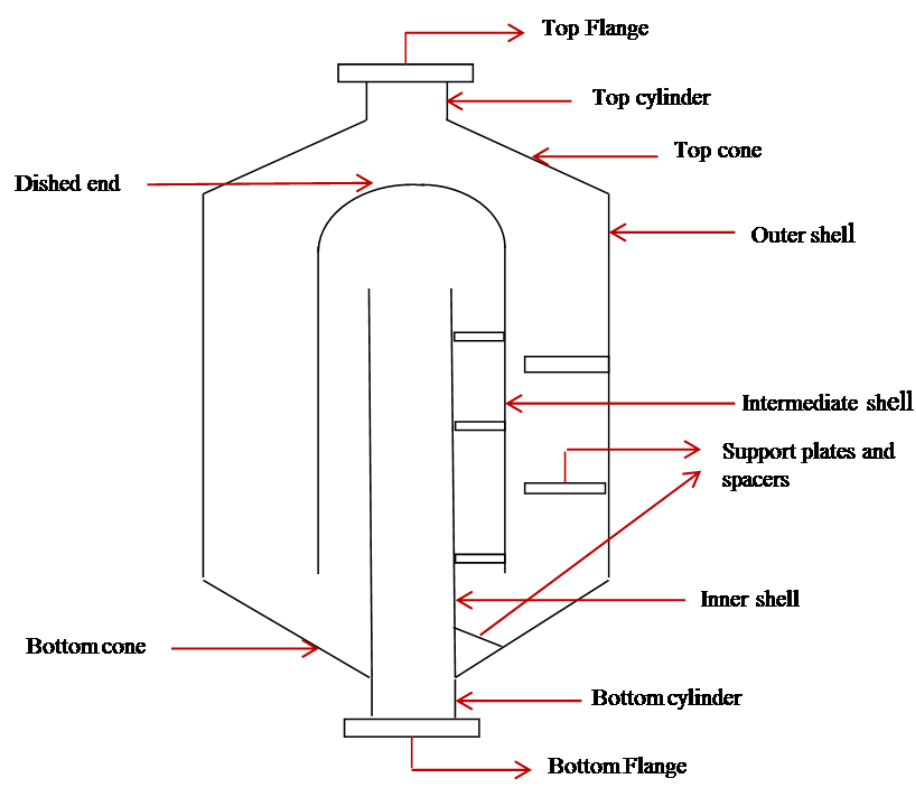

Fig. 1. Schematic diagram of Molecular seal Drum

the baffle to seal diameter ratio should not be more than 0.75 when hydrocarbons are burned in the flare $[2,8,9]$.

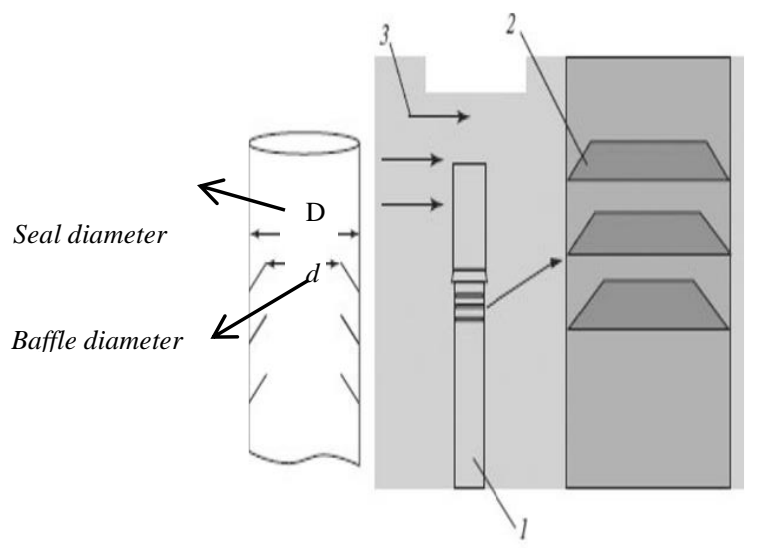

Fig. 2. Velocity seal simulation model: 1) Flare stack; 2) Baffles; 3) Wind [2] 


\section{International Journal of Engineering Applied Sciences and Technology, 2020 \\ Vol. 4, Issue 9, ISSN No. 2455-2143, Pages 272-275 \\ Published Online January 2020 in IJEAST (http://www.ijeast.com)}

\section{DISCUSSION}

It is known that these seals are used to reduce purge gas quantity and for safe operation of flare system but the comparison between these two cannot be made on the basis of safety. As far as safety is concerned there is hardly a difference on the basis of which these seals can be preferred.

To determine the purge gas rate, $\mathrm{Q}$, for continuous purge requirements in open flares without the effect of these seals, following equation can be used [1]:

$$
Q=190.8 D^{2.46}\left[\frac{1}{y} \ln \left(\frac{20.9}{o_{2}}\right)\right] \times F_{b} \quad m^{3} / h
$$$$
Q=0.07068 D^{2.46}\left[\frac{1}{y} \ln \left(\frac{20.9}{O_{2}}\right)\right] \times F_{b} \quad f t^{3} / h \text {-.-- }(2)
$$

Where

$\mathrm{D}=$ Flare stack diameter, expressed in $\mathrm{m}$ (in.)

$\mathrm{Y}=$ Distance from stack tip, expressed in $\mathrm{m}$ (ft.)

$\mathrm{O}_{2}=$ Oxygen concentration, expressed as percentage

$\mathrm{F}_{\mathrm{b}}=$ Gas buoyancy factor

$\mathrm{F}_{\mathrm{b}}=6.25\left[1-0.75\left(\frac{\mathrm{M}_{W}}{28.96}\right)^{1.5}\right]$

For an instance, if we consider a tip of 34 inch diameter and Nitrogen as purge gas, the required purge flow, Q is as follows:

Without seals: $18-19 \mathrm{Nm}^{3} / \mathrm{hr}$.

Velocity Seal: $7-8 \mathrm{Nm}^{3} / \mathrm{hr}$.

Molecular Seal: 3-4 $\mathrm{Nm}^{3} / \mathrm{hr}$.

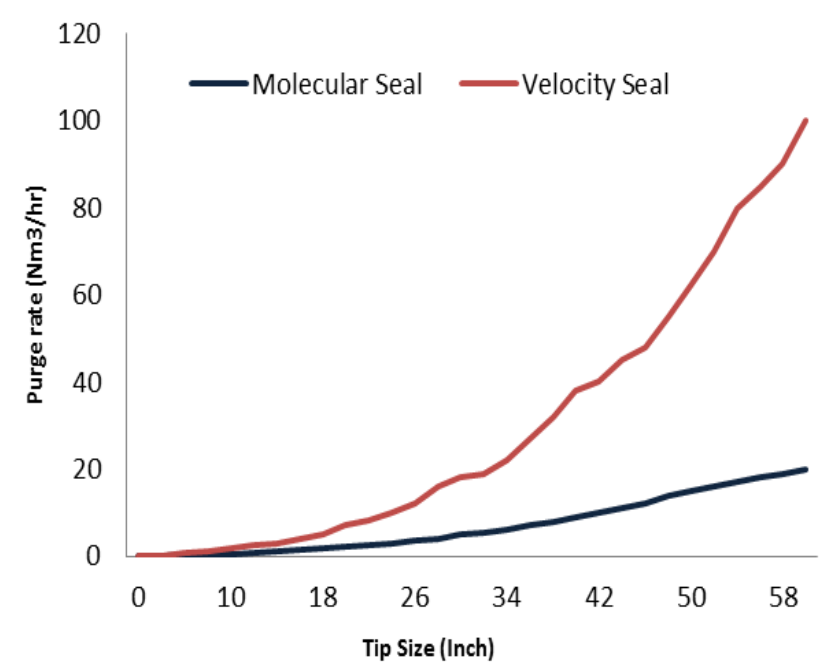

Fig. 3. Graph showing purge rate for different tip size for Molecular seal and Velocity seal

The purge flow rate for both the seals are calculated which is shown in Figure 3 which indicates that the difference in purge rate is significant when we move to the higher diameter of the tip whereas below a certain size the difference is negligible. Many researchers have claimed this reduction to be up to $98 \%$ in case of molecular seal. Table 1 show the comparison of velocity seal and molecular seal but it can be assumed that the criteria of selection always depend on the circumstances under which the system is to operate.

Table.1. Comparison of Molecular seal and velocity Seal

\begin{tabular}{|l|l|}
\hline \multicolumn{1}{|c|}{ Molecular seal } & \multicolumn{1}{|c|}{$\begin{array}{c}\text { Velocity seal (Diode pine } \\
\text { cone seal) }\end{array}$} \\
\hline $\begin{array}{l}\text { It uses difference in densities } \\
\text { of purge gas and ambient air } \\
\text { to keep air from entering the } \\
\text { flare system. }\end{array}$ & $\begin{array}{l}\text { It uses the kinetic energies of } \\
\text { purge gas prevent air entry } \\
\text { into the flare stack. }\end{array}$ \\
\hline $\begin{array}{l}\text { Lowest possible purge rate } \\
\text { reduction of up to } 98 \% \text { ) and } \\
\text { operating costs. }\end{array}$ & $\begin{array}{l}\text { Purge rate is higher than } \\
\text { molecular seal but much less } \\
\text { than without seal. }\end{array}$ \\
\hline $\begin{array}{l}\text { Zero percent oxygen below } \\
\text { the seal. }\end{array}$ & $\begin{array}{l}\text { Oxygen level below the seal } \\
\text { is under 4-8\%. }\end{array}$ \\
\hline $\begin{array}{l}\text { Extended protection in the } \\
\text { event of loss of purge. }\end{array}$ & $\begin{array}{l}\text { It act as a physical barrier to } \\
\text { air penetration down the } \\
\text { inside wall of riser and } \\
\text { maximizes the velocity of } \\
\text { flare gas which further } \\
\text { reduces the risk of air ingress. }\end{array}$ \\
\hline $\begin{array}{l}\text { Structural wind load is } \\
\text { increased due to the drum } \\
\text { installation. }\end{array}$ & $\begin{array}{l}\text { Inexpensive to operate and } \\
\text { install (since it is made as an } \\
\text { integral part of the tip). }\end{array}$ \\
\hline $\begin{array}{l}\text { Installation cost is too high. } \\
\text { load. }\end{array}$ \\
\hline
\end{tabular}

\section{CONCLUSIONS}

The main purpose of purging is to provide sealing so as to prevent the ingress of air into the flare stack. If the flow to vent/flare stack stops for some reason, we have to pre-purge before flare startup. The pre-purge displaces any existing air from the stack and continuous purge ensures that atmospheric air does not enter the stack through the flare. Based on the observation and studies, following conclusions can be drawn:

1. Though molecular seal provides extended protection in the event of loss of purge, it is never recommended to stop the 
purge gas for any reason during plant running condition. So, the point of consideration holds no stand for the selection of seals on the basis of this reason.

2. It is widely known that Molecular seal increases the structural wind load due to its robust construction, therefore Velocity seals can be preferred so as to eliminate any such risk.

3. According to the earlier experience, velocity seals have self-draining capability which is not so in case of Molecular seals and hence the latter is provided with drain point which if gets plugged due to corrosion products like condensate/rain water freezing, or refractory debris from refractory lined flare tip, results in hazardous situation.

4. The velocity seals have no hazard situations in running conditions unless some abnormal condition prevails. It is also claimed that molecular seal is safer than velocity seal but observations proved no such facts and moreover the installation cost is much less for the latter which proves its preference over the former.

5. It is a fact that the purge rate for molecular seal is much less than velocity seal but our calculation proves that up to 16 inch diameter of tip, there is no significant difference in purge rate for the two seals, hence velocity seal is an economic option to replace molecular seal up to the said diameter of tip.

6. It is recommended to use velocity seal with water seal drum for the safest operation of system but in Middle East countries, the flare system is also commissioned with velocity seal only and hence the choice of the same depends on the customer's requirement.

\section{REFERENCE}

[1] D. Shore (1996), "Making the flare safe," Journal of Loss Prevention in the Process Industries, 9, No. 6, 363-381.

[2] Yong-Zhong Bai, Peng Wang, and Jun-cheng Jiang January, 2014: Determination of the minimum purge gas flow rate in flare systems with a velocity seals, Chemistry and Technology of Fuels and Oils, Vol. 49, No. 6, (Russian Original No. 6, November- December, 2013).

[3] H. W. Husa, "How to compute safe purge rates," Hydrocarbon Processing and Petroleum Refiner, 43, This work was supported by the National Basic Research Program of China (program 973), grant No. 2010 CB226902.

[4] API Standard 52, Sixth edition, (January 2014) : Pressure relieving and depressurizing systems.

[5] API standard 537, second edition, (December 2008): Flare details for general refinery and petrochemical service.

[6] S. H. Tan (1967), "Flare system design simplified," Hydrocarbon Processing, 46, 172-176.

[7] S. G. Bryce and R. E. J. Fryer-Taylor (1994), "Reducing the purge in hydrocarbon vent stacks," Journal of Loss Prevention in the Process Industries, 7, No. 3, 249-255.
[8] V. I. Panchenko (1993), "Determining the safe purge rates for flare tubes," Chemical and Petroleum Engineering, 29, No. 5, 205-209.

[9] W. Y. Dang and A. F. Yu (2010), "Study on the design pressure for water-sealed drum in refinery flare system," China Safety Science Journal, 20, No. 9, 75-80.

[10] H. W. Husa (1977), Purging Requirements of Large Diameter Stacks, paper presented at the Fire/Safety Engineering Subcommittee of the American Petroleum Institute, Fall 1977 Meeting, September 13-15, San Francisco, California.

[11] G. R. Kent (1964), "Practical Design of Flare Stacks," Hydrocarbon Processing and Petroleum Refiner, Volume 43, Number 8, pp. 121-125.

[12] NFPA 69, Explosion Prevention Systems. 